\title{
Understanding the Behavior of Domestic Emus: A Means to Improve Their Management and Welfare-Major Behaviors and Activity Time Budgets of Adult Emus
}

\author{
Deepa G. Menon, ${ }^{1,2}$ Darin C. Bennett, ${ }^{2,3}$ and Kimberly M. Cheng ${ }^{2}$ \\ ${ }^{1}$ Southern Research and Outreach Center, University of Minnesota, Waseca, MN 56093, USA \\ ${ }^{2}$ Avian Research Centre, Faculty of Land and Food Systems, University of British Columbia, 2357 Main Mall, \\ Vancouver, BC, Canada V6T 1Z4 \\ ${ }^{3}$ Animal Science Department, California Polytechnic State University, San Luis Obispo, CA 93407, USA \\ Correspondence should be addressed to Deepa G. Menon; drajumen@umn.edu
}

Received 22 August 2014; Revised 29 September 2014; Accepted 14 October 2014; Published 5 November 2014

Academic Editor: Tetsuya Matsuura

\begin{abstract}
Copyright ( 2014 Deepa G. Menon et al. This is an open access article distributed under the Creative Commons Attribution License, which permits unrestricted use, distribution, and reproduction in any medium, provided the original work is properly cited.
\end{abstract}

\begin{abstract}
Information on domestic emu behavior is sparse and hence a study was undertaken to identify and describe the behavior of domestic emus in a farm setting. The behavioral repertoires, activity time budgets, effect of time of the day, sex, weather, and relative humidity on activities of adult emus were investigated. Eight randomly selected emus were observed using one-zero sampling method for 12 days, each period of observation lasting 30 minutes. The major behavioral categories identified were ingestive drinking, standing, locomotion, grooming, socialization, vocalization, and resting. The emus spent most of their time walking, standing, and eating. Immediately after moving to a new pen, emus were found to huddle together to keep away from emus already resident in the pen. The time spent on each activity was not significantly different between the sexes. The findings from this study provided important information on the behavior and activities of emus. The observed behaviors need to be further examined to assess their relations to the birds' welfare.
\end{abstract}

\section{Introduction}

Emus are native to Australia and are farmed worldwide for fat (emu oil), meat, and leather. Despite a long history of use of emu oil for wound healing by the aborigines, it was only in the 1970s that the Australian Government gave permission to capture 300 wild emus to establish a primary breeding stock for domestication. The commercial farming of emu began only in the late 1980s and then the industry spread to Europe, North America, Asia, and Africa [1]. Current popularity of emu farming in the USA [2] and India [3] warrants the need to understand the behavior of these birds. It also becomes increasingly important to understand behavior repertoires for improving husbandry practices and interpreting welfare implications [4].

Understanding the feelings in animals through behavioral observations is a vital step in improving their welfare [5]. An animal's welfare is compromised when it is having difficulty in coping with its environment [6], when in pain, when feeling fear, or when being unable to control its interactions [7]. Animals respond to stress through a variety of coping mechanisms involving the HPA (hypothalamic-pituitary-adrenal) and SA (sympathoadrenal) axis, leading to physiological and behavioral changes [8]. Hence, changes in the repertoire and time budgets of poultry could indicate welfare issues [9, 10]. Behavioral changes would encompass unusual, repetitive (stereotypic) actions as well as the absence of normal behavior of the species.

Among ratites (emu, ostrich, kiwi, rhea, cassowary, and tinamou), the behavior of ostriches has been considerably researched [11]. Studies conducted on the behavior of ostriches have identified behavior groups such as sitting, standing, pacing, walking, foraging, feeding [11], inactive, locomotive, ingestive, ground pecking, object pecking, preening, aggression (hiss/beak gapes, threat display, 
chase, run-chase, chest ramming, kicking, mounting, and trample $[4,12])$.

In one study, the behavior of emus has received very little attention [13-16]. The behavior of emus after declawing was described under six major categories, namely, inactive, ingestive, posture change, grooming, aggression, and locomotion [17]. There are few studies conducted on specific behaviors of emus such as sleep [13], reproduction [18], vigilance [19], and an abstract on emu chick behaviors [20]. The only published research study on emu behavior [14] was conducted on young emus (less than 2 years of age) from Australia and Britain. This study did not describe their behavior or conduct any statistical analysis.

Therefore, it was decided to determine the behavior repertoires and time budgets in adult domestic emus (above five years of age) in Canada. The intention was to establish a list of common behaviors to be utilized for further studies on their welfare.

The objectives of the current study were to

(1) identify and describe major behavior components;

(2) establish the activity time budgets;

(3) determine the effect of time of the day, sex, and weather on activities of adult domestic emus.

These data could be utilized to build a knowledge base on emu behavior for assessment of their welfare.

\section{Materials and Methods}

This study was carried out under the University of British Columbia Animal Care permission \# A10-0104.

2.1. Management. Four pairs of adult emus (above 5 years of age) were observed in the postbreeding season, just after the cessation of egg laying (late spring, early summer). Emus were housed in a large outdoor pen $(28 \times 45$ feet $)$ containing natural forages that was located at the large animal care facility of the University of British Columbia. After completion of this study, emus were housed in two pens of the same dimension $(28 \times 45$ feet), so as to observe their behavior when separated from conspecifics. Emus had ad libitum access to pelleted ratite feed (Otter Co-op, Aldergrove, British Columbia, Canada) and drinking water. Each emu was identified according to the differences in colouration and markings on their body. The sex of the emus was determined by cloacal palpation [21] at the end of the study.

2.2. Observations. A blind was set up at a good vantage point outside the emu pen, one week prior to the study. The observer spent one hour in the blind every day for the emus to acclimatize to the observer getting in and out of the blind and also to refine the observation protocols. The emus were observed for 30-minute periods in the morning (07:00 a.m. to 09:00 a.m.) and late afternoon (3:00 p.m. to 5:00 p.m.) for 20 days prior to the start of the experiment to get a probable set of activities for constructing a behavior repertoire. The description of each of the behavior categories was also noted down and thus a data recording sheet was developed (Table 1). A behavior that lasted for the whole observation interval (30 seconds) was classified as a state. Those behaviors that were shorter in duration (less than 30 seconds) were classified as events [22]. During scoring, no distinction was made between states and events and between single and multiple occurrences during the interval.

The main study was conducted over a 12 -day period, during which the behavior of individual emus in their natural group setting was recorded for four 30-minute long observational sessions per day so as to record the behavior of each emu for at least six hours. Each observational session (30 minutes) was divided into sixty 30 -second intervals. All the occurring events were noted down using one-zero sampling technique [23]. All behaviors which did not occur in a particular interval were scored zero, while those that occurred were scored one [22]. During each observational session, two randomly selected emus were observed at the same time, such that all eight emus were observed each day. There were two observation sessions in the morning and two in the late afternoon of 30-minute duration. There was a 30-minute break after each observation period to avoid observer fatigue. This period also coincided with the time following the checking of pens by the care-takers (handlers). Each emu was observed for a minimum of 10 hours prior to the commencement of the study and then for six hours during the study. All of the activities of emus were recorded during the 480 intervals and then the one-zero scores for each behavior were calculated [22]. The routine management of these emus was not disrupted and therefore how these emus reacted to their care-takers was also evaluated.

The behavioral patterns of these emus were also observed for five days (one hour each in the morning and noon) after they were regrouped and housed in separate pens, so as to identify unusual behaviors. The behavioral events and responses to handlers during handling for regrouping were also noted down. The meteorological data including temperature, humidity, and weather condition were also noted (http://www.climate.weatheroffice.gc.ca) during the different observation periods and categorized for analysis.

The weather conditions recorded under six categories were scored as follows.

(1) clear $=1$, (2) mainly clear $=2$, (3) mostly cloudy $=3$, (4) cloudy $=4,(5)$ rain showers $=5$, and (6) rain $=6$.

The relative humidity was recorded under three categories as follows: (1) low $=47-60 \%$, (2) medium $=61-71 \%$, and (3) high $=72-83 \%$.

2.3. Statistical Analysis. The mean one-zero score of each of the behaviors for individual emus was calculated by summing the total observations (ones) and dividing by the total number of periods so as to produce the corresponding one-zero scores. Then the activity time budget [26] for the morning and late afternoon sessions was calculated as

Time budget

$$
=\frac{\text { number of intervals for the behavior }}{\text { total no of intervals }} \times 100 .
$$


TABLE 1: List of behaviors of emus and their descriptions.

\begin{tabular}{|c|c|c|}
\hline Number & Behavior & Description \\
\hline \multicolumn{3}{|r|}{ (I) Ingestion } \\
\hline (1) & Eating & Consuming the concentrate feed. \\
\hline (2) & Foraging & Searching for and consuming the fodder in the field. \\
\hline (3) & Picking & Picking up feed/poking on ground/pecking objects. \\
\hline$(4)$ & Voiding & Elimination of droppings. \\
\hline \multicolumn{3}{|r|}{ (II) Drinking } \\
\hline$(5)$ & Drinking & Touching water surface with the beak with or without gulping action. \\
\hline \multicolumn{3}{|r|}{ (III) Grooming } \\
\hline (6) & Preening & Self-preening with the beak. \\
\hline (7) & Dust bathing & Rubbing the neck or any portion of body against the ground, shaking both wings either crouching or sitting. \\
\hline (8) & Feather picking & Pecking at the feathers of other emus. \\
\hline (9) & Body shaking & Shaking body/wings while standing. \\
\hline (10) & Head shaking & Shaking the head. \\
\hline
\end{tabular}

(11) Standing Standing

\begin{tabular}{lcl}
\hline & & \\
(12) & Running & Running sprints (with or without the wing extended) but not chasing other emus. \\
$(13)$ & Walking & Walking with or without the wings extended. \\
$(14)$ & Parallel walking & Walking together with no attempt to attack each other. \\
$(15)$ & Pacing & Walking parallel to and along the fence. \\
\hline
\end{tabular}

(VI) Socialization

(16) Aggression Attacking other emus (contact between bodies by kicking/pushing).

(17) Threatening Standing tip-toed and making a hissing sound towards other emus.

(18) Chasing Chasing an emu away with or without running after it, causing it to flee, retreat, or react.

$\begin{array}{lcl}\text { (19) } & \text { Drumming } & \text { Sound produced by the female emu }[24,25] \\ (20) & \text { Grunting } & \text { Sound produced by the male emu }[24,25] . \\ (21) & \text { Distress calling } & \text { A deeper grunt produced by both male and female emus while being handled. }\end{array}$

\begin{tabular}{lll}
\hline & & (VIII) Resting \\
(22) & Sleeping & Standing/sitting still with eyes closed (not handled or threatened by other emus). \\
$(23)$ & Sitting & Crouching/sitting with or without the head raised.
\end{tabular}

(24) Yawning Opening mouth briefly and closing it.

(25) Pecking fences Pecking at the fence wire or post.

Twenty-five behavior types listed (Table 1) were summarized into eight major categories. The main effects of time of the day and emus and their interaction on time budgets were tested using a two-way ANOVA. For determining the effect of weather condition and relative humidity on behavior, separate one-way ANOVA or Kruskal-Wallis ANOVA on ranks was done. The post hoc tests done were Bonferroni test or Dunn's test, respectively. Mann-Whitney $U$ test was done to compare the differences in time budget between sexes. Wilcoxon matched pair test was done to compare the difference in time budget within an individual during the two time periods of the day. All results were interpreted at a significance level of 0.05 using Statistica 10 (Statsoft Inc., Tulsa, OK, USA). Spearman correlation coefficient $\left(r_{s}\right)$ was used to determine the linear relationship between the continuous variables studied and also the association between categorical and continuous variables. Point biserial correlation $\left(r_{\mathrm{pb}}\right)$ (XLstat version 2012. 1. 01, NY, USA) was used to study the relationship between periods of the day and the continuous variables.

\section{Results}

3.1. Behavior of Emus. The major categories of behavior identified from among all those observed (Table 1) were ingestive, drinking, grooming, standing, locomotion, socialization, vocalization, resting (sitting, sleeping), and others.

3.1.1. Ingestive Behavior. This included feeding on concentrate feed pellets in the feed trough, foraging on insects and plant material, and picking up stones and ingesting them (Table 1). Refilling of feed troughs in the morning was found to stimulate the emus to eat the concentrate feed. The three dominant emus (judged by how frequently they 
TABLE 2: Categories of temperament of emus towards regular care-takers.

\begin{tabular}{ll}
\hline Categories & Description \\
\hline Friendly & Approach the care-taker and stay close to the care-taker. Head is kept down. \\
Docile & Would not mind having the care-taker in close proximity but would not approach the care-taker. Head is kept down. \\
Cautious & Would move away from the care-taker and stay at a distance watching the care-taker. Head is not always down. \\
Panicky & Would move or run away from care-takers, keeping a distance. Head is kept high; may pace at a distance from the care-takers. \\
Flighty & Would bolt at the sight of care-takers, running against fences. \\
\hline
\end{tabular}

displaced other emus from the feeding trough) were the first to approach the feed trough. Other emus were found to wait for these emus to move away before approaching the feed trough. While foraging, emus walked across the pens, pausing in between to nib at the grasses and other foliage inside the pen. They were also found to pick up stones from the ground or just peck at the ground while grazing.

3.1.2. Grooming Behavior. Emus frequently preen feathers with their beaks and they do this while sitting, standing, or walking. Emus were found to preen feathers very frequently on rainy days. They lack preen glands and hence their feathers become quite moist when exposed to rain.

3.1.3. Resting Behavior. Emus were found to rest with their eyes closed while standing or in the sitting position for periods ranging from thirty seconds to three minutes. Emus sit on their hocks in the squatting position and they would eat, drink, preen, and even forage from this position. They would also sit with just the ventral portion of the body touching the ground or with the whole length of the neck also in contact with the ground. Emus preferred to sit under the sun with their neck extended and even rest or sleep at dusk and early in the morning in the sitting position.

3.1.4. Vocalizations. The vocalizations included "drums" by female and "grunts" by male emus (Table 1). There was considerable variation in the loudness, duration, and pitch of these calls among individuals.

3.1.5. Other Behaviors. Emus would also infrequently peck at the fences, wooden poles, and other plants inside the pen while grazing. Emus drank by using their beak to scoop up the water, shaking their head while gulping and pausing in between. They liked to splash water on their body and would dip themselves in large drinking water troughs. Their activities were not generally interrupted by rain and we have never observed them seeking shelter when it was raining. Emus were startled by the slightest noise and then they would stop all their activities and became vigilant. Usually at least one of the emus kept watching while others were feeding.

3.1.6. Unusual Behaviors. Emus which were separated from conspecifics continuously paced along the fences without eating or foraging. Immediately after changing pens, emus were found to huddle (stay in groups in one corner) away from the emus already present in the pen. Another behavior observed after regrouping was repetitive pecking at the

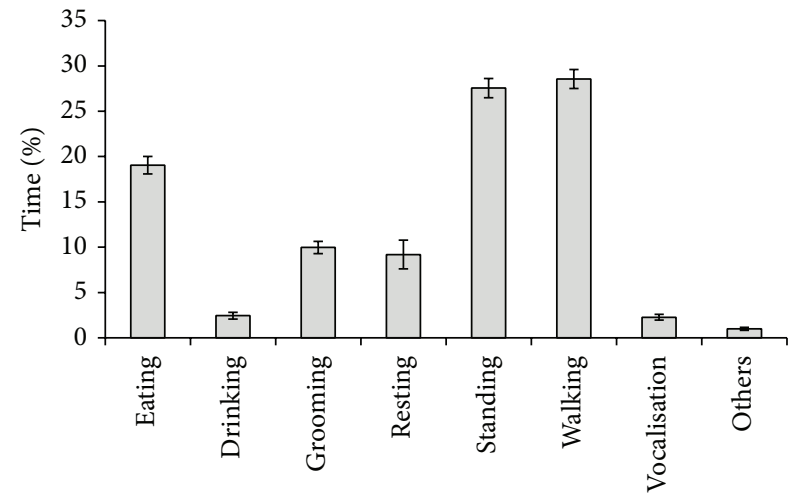

Behaviour

FIGURE 1: Activity time budgets for major eight behavior categories of emus. Mean time budgets (\%) for each behavior category with the standard errors are presented.

fences. Responses to handlers included running into fences, jumping, kicking, slipping, stopping (balking), falling, and sitting (disinclination to move).

3.2. Temperament. The temperament of these emus inside the pen was noted down on all the 12 days during the time when care-takers were inside the pen to provide feed or water. Their behavioral response to care-takers was classified as friendly, docile, cautious, panicky, and flighty (Table 2). These categories were not mutually exclusive. From our observations, two of the emus were friendly and docile while three of them were cautious and docile. The other three were panicky. There were no flighty emus in this group. We could notice bouts of aggressive behavior during this study among two female emus only. None of the emus were aggressive towards their care-takers.

3.3. Activity Time Budgets. The mean total activity score (one-zero scores) of an emu during a 30-minute observation period was found to be $120 \pm 32$. The atmospheric temperature during the period of study varied from $12.9^{\circ}$ to $26.2^{\circ} \mathrm{C}$, while the relative humidity $(\mathrm{RH})$ varied from 47 to $83 \%$. The activity time budgets (eight major behaviors) given in Figure 1 showed that emus spent most of their time walking, standing, and eating.

The time budgets for the time periods (morning and noon hours) are given in Table 3. The emus stood for significantly longer $(P=0.02)$ duration in noon than in the morning period and walked significantly $(P=0.03)$ less in the noon. There was no significant difference between the sexes for any 
TABLE 3: Activity time budgets for major behavior for emus, relative humidity, and temperature during morning and noon hours ${ }^{1}$.

\begin{tabular}{lccc}
\hline Variables & $\begin{array}{c}\text { Morning } \\
\text { Mean } \pm \text { S.E. }\end{array}$ & $\begin{array}{c}\text { Noon } \\
\text { Mean } \pm \text { S.E. }\end{array}$ & $P$ value \\
\hline Feeding & $18.2 \pm 1.3$ & $19.9 \pm 1.3$ & NS \\
Drinking & $2.8 \pm 0.5$ & $2.1 \pm 0.5$ & NS \\
Grooming & $9.8 \pm 0.0$ & $10.2 \pm 0.9$ & NS \\
Resting & $10.2 \pm 2.3$ & $8.2 \pm 2.3$ & NS \\
Locomotion & $31.0 \pm 1.5$ & $26.1 \pm 1.4$ & 0.02 \\
Standing & $25.2 \pm 1.5$ & $29.9 \pm 1.5$ & 0.03 \\
Vocalization & $1.9 \pm 0.4$ & $2.6 \pm 0.4$ & NS \\
Other behaviors & $0.9 \pm 0.2$ & $1.1 \pm 0.2$ & NS \\
Relative humidity $(\%)$ & $68.1 \pm 1.0$ & $56.9 \pm 0.9$ & \\
Temperature $\left({ }^{\circ} \mathrm{C}\right)$ & $17.4 \pm 0.4$ & $17.3 \pm 0.6$ & \\
\hline
\end{tabular}

${ }^{1}$ Least square means \pm standard error are presented.

NS: not significant.

major behavior. There was no significant effect of weather condition or temperature on the time budgets.

3.4. Relationships among Behavior Components. The linear relationship between the following variables was significant $(P<0.05)$. Locomotion was positively correlated to eating $\left(r_{s}=0.27\right)$ and grooming $\left(r_{s}=0.25\right)$. Resting was negatively correlated to eating $\left(r_{s}=-0.32\right)$ and vocalization $\left(r_{s}=\right.$ $-0.25)$. The emus stood more when the RH was less $\left(r_{s}=\right.$ $-0.26)$. The variable standing and the period of the day were significantly associated $\left(r_{\mathrm{pb}}=0.26\right)$ indicating that emus spent more time standing in the afternoon observation periods.

\section{Discussion}

A thorough understanding of the behavioral needs of emus is important to ensure better management and welfare. However, the behavioral repertoire of emus has received very little attention [14]. In this study we observed and described the behavior of adult emus in the post- breeding period. Examination of the behavioral repertoire of emus is important to better understand the changes consequent to stress [15] (this information was used in a study on transport stress in emus [27]). As one-zero scores are correlated to both frequency and duration of behavior [28], our sampling technique may be considered to be a good method to record events and intermittent behavior $[22,28]$. The shorter durations of the time intervals selected, that is, 30 seconds, helped to improve the reliability of the findings [28].

The activity time budget was determined on a yes/no basis within a certain period. Use of the same observer in the study was essential to be consistent in determining the occurrence of behavior (whether it was a yes or a no). A single trained observer was used for the same as more than one observer would create variation in the measurement. The observation period was short enough to avoid observer fatigue. The observer is "blind" to the treatment; that is, sex of the birds was determined only after completion of the experiment.

The findings from this study are applicable to domestic emus maintained in farms in Canada. The behaviors described are based on the descriptions made by the observer prior to the study and verified by external experts. The behaviors observed and described in the male and female emus included in this study were later tested in field experiments conducted in a private farm in Saskatchewan [27] and were found to be similar, thus confirming the validity of the findings made in this study.

4.1. Behavior of Emus (Table 1). In general, emus seem to have similar behavior as that of other ratites such as ostriches $[4,29-31]$ and rheas $[32,33]$. The behaviors of emus observed in this study were classified based on previous studies of ostriches $[4,11,12,29]$. Incidental observation of behavioral responses is considered helpful in assessing the potential impacts of common management practices on animals [34]. Sitting with just the ventral portion of the body touching the ground or with the whole length of the neck also in contact with the ground appeared to be the resting behavior in these birds (emus [13] and ostriches [29]). Emus sleep in this position at dusk and early in the morning [13], but none of these studies reported them standing with eyes closed. Vigilance behavior in emus has been reported in free-living wild emus [19] but has not been reported in farm emus. These emus spend considerable amount of time standing vigilant rather than foraging or resting [30]. It has been observed that birds with interrupted sleep fall asleep for few seconds in a semialert state with a single eye still kept open $[35,36]$. Similarly, it is likely that emus which are on vigil had curtailed night sleep and had been involved in "micronaps," with either one or two eyes closed.

The inclination to play in water is known [20] and hence could be suggested as a means to enrich pens and thus promote the welfare of emus, especially in summer. The dominance shown by females was evident as some of them were always successful in displacing others from the feed trough. Weaker, smaller, and subordinate birds in the group are usually displaced at the feed bin by bigger, healthier, and dominant emus [37]. The aggressive behavior of emus observed in this study is comparable to that in ostriches [12].

Emus are curious birds and spend considerable amount of their time in beak related activities including foraging, preening, and pecking at the ground and other objects in the pen. Emus also pick up stones and grit while feeding, which is found to help them in digestion [38]. In cases where there is inadequacy of substrates and forages inside the pen, emus might have a very limited activity choice. At such times, it is likely that they spend more time pecking inanimate objects [39] especially when they experience boredom. This points to the need for environmental enrichments in pens to improve the welfare of these birds. However, separation of emus into groups led to fence pecking which appears to be their means to express frustration.

Pacing has been reported as a predominant activity in ostriches [4, 30], rheas [33], and emus [14]. It is also at times referred to as an abnormal behavior due to frustration and/or 
confinement [29], if done stereotypically [14]. Hence it is important to consider the time budgets over a period of time to know the drive behind this behavior. Increase in displacement activities [40] such as pacing is induced by confinement, movement restriction [41], and social reorganisation [34]. This is an indicator of stress in emus [42, 43], ostrich [11,44], and chicken $[45,46]$ and a mechanism to overcome the stress [47].

Huddling is the first line of response to a strange environment [48] and also an attempt to reduce heat loss from the body. So, in emus, the focus should be on these three behaviors while comparing time budgets.

Though we noticed few bouts of aggressive behavior during this study, it was not seen in all emus and was not very frequent. Aggression in female emus is commonly noticed during the breeding season and otherwise they have a docile temperament $[18,24,49]$. As emus have a different temperament in the breeding season, it is likely that human interventions might add to the stress they are already experiencing. Any attempt to interfere with the social orders through regrouping or transportation during this period might prove extremely stressful and hence should be avoided.

Observations on the response of emus to handlers showed that training them or maintaining constant contact would help to reduce flighty responses, making handling easier. Thus stockmanship has an important role in their welfare.

4.2. Activity Time Budgets. Our findings showed that adult emus spent most of their time in locomotion and standing, whereas a previous study in younger emus reported sitting as the major activity [14]. In this study, emus were found to stand more in the latter half of the day, as they had a more active foraging period in the morning. Similar temporal variation in activities has been reported in ostriches [30, 50, 51]. We could not find any significant effect of sex on the activity time budgets in emus, probably as the period of study was after the end of breeding season in Canada.

Activity time budgets are often used as a diagnostic tool to assess adjustments made by animals to the behavior homeostasis on exposure to stressors [52]. To study the impact of stress on emus, it is important to focus on the changes in normal behavior (stereotype or absence) and identify unusual ones. Behavioral changes $[53,54]$, such as stereotypies [7, 55, 56] and vocalization [57], could provide greater insight into the physical and emotional status of these birds and have to be studied in greater detail.

\section{Conclusion}

This study did succeed in collecting valuable information on the different behavior as well as patterns thereof in adult emus in Canada, in an experimental farm setting. Activity time budgets before and after an intervention could be utilized to evaluate behavior changes and thus the stress experienced by these birds. Emu behavior was unaffected by sex. The findings from this study could be utilized to build a knowledge base on the relationship between behavior and welfare of emus.

\section{Conflict of Interests}

The authors hereby declare that there is no conflict of interests regarding the publication of this paper.

\section{Acknowledgments}

The funding for this study was provided by the British Columbia Ministry of Agriculture and Lands, with funds administered by the University of British Columbia, Specialty Birds Research Committee. The authors thank Arthur Vanderhorst, Ira, and Ray Gopaul of the Large Animal Care Facility, South Campus, University of British Columbia, Vancouver, Canada, for taking care of the emus. Drs. David Fraser and Raja RajaMahendran provided valuable inputs on an earlier version of this paper.

\section{References}

[1] R. S. Thompson, "Raising emus and ostriches," Farming Systems Information Center, 1997, http://afsic.nal.usda.gov/.

[2] G. L. Todd, The metabolic profile of cardiac and skeletal muscle tissue from captive emus (Dromaius novaehollandiae) raised in Northern Colorado: implications for assessing muscle health for emus with splayed-leg disorder [M.S. thesis], Colorado State University, Fort Collins, Colo, USA, 2012.

[3] R. Gujral, Emu-This Bird Means Business, vol. 8, Science Tech Entrepreneur, 2009, http://www.indg.in/agriculture/animalhusbandary/poultry/emu-rearing.pdf.

[4] D. Csermely, G. Gaibani, and E. Dardani, "Year-round behavioural sequences in captive ostrich (Struthio camelus domesticus) pairs," Applied Animal Behaviour Science, vol. 103, no. 1-2, pp. 156-166, 2007.

[5] S. Watanabe, "How animal psychology contributes to animal welfare," Applied Animal Behaviour Science, vol. 106, no. 4, pp. 193-202, 2007.

[6] D. M. Broom, "Behaviour and welfare in relation to pathology", Applied Animal Behaviour Science, vol. 97, no. 1, pp. 73-83, 2006.

[7] P. R. Wiepkema, "Developmental aspects of motivated behavior in domestic animals," Journal of Animal Science, vol. 65, no. 5, pp. 1220-1227, 1987.

[8] R. M. Sapolsky, L. M. Romero, and A. U. Munck, "How do glucocorticoids influence stress responses? Integrating permissive, suppressive, stimulatory, and preparative actions," Endocrine Reviews, vol. 21, no. 1, pp. 55-89, 2000.

[9] G. S. Sanotra and C. A. Weeks, "Abnormal behavior and fear," in Measuring and Auditing Broiler Welfare, C. A. Weeks and A. Butterworth, Eds., chapter 6, pp. 71-80, CABI Publishing, Cambridge, Mass, USA, 2004.

[10] H. Mollenhorst, T. B. Rodenburg, E. A. M. Bokkers, P. Koene, and I. J. M. De Boer, "On-farm assessment of laying hen welfare: a comparison of one environment-based and two animal-based methods," Applied Animal Behaviour Science, vol. 90, no. 3-4, pp. 277-291, 2005.

[11] D. C. Deeming, "A note on effects of gender and time of day on the winter time-activity budget of adult ostriches (Struthio camelus) in a farming environment," Applied Animal Behaviour Science, vol. 59, no. 4, pp. 363-371, 1998.

[12] A. Meyer, S. W. P. Cloete, C. R. Brown, and S. J. van Schalkwyk, "Declawing ostrich (Struthio camelus domesticus) chicks to 
minimize skin damage during rearing," South African Journal of Animal Sciences, vol. 32, no. 3, pp. 192-200, 2002.

[13] K. Immelmann, “The sleep of Emu," Emu, vol. 60, no. 3, pp. 193195, 1960.

[14] J. Sales and J. Horbañczuk, "Time activity budget of emu (Dromaius novaehollandiae) under different farming conditions," Animal Science Papers and Reports, vol. 16, no. 4, pp. 265-269, 1998.

[15] P. C. Glatz, "A benchmark study of husbandry, transport, lairage and slaughter to improve skin quality of ratites," RIRDC Publication Emus, vol. 2, pp. 1-229, 2000.

[16] V. R. Patodkar, S. D. Rahane, M. A. Shejal, and D. R. Belhekar, "Behavior of emu bird (Dromaius novaehollandiae)," Veterinary World, vol. 2, no. 11, pp. 439-440, 2009.

[17] P. C. Glatz, "Effect of declawing on behavior of farmed emus," Asian-Australasian Journal of Animal Sciences, vol. 14, no. 2, pp. 288-296, 2001.

[18] D. Blache, C. D. Barrett, and G. B. Martin, "Social mating system and sexual behaviour in captive emus dromaius novaehollandiae," Emu, vol. 100, no. 3, pp. 161-168, 2000.

[19] C. R. J. Boland, "An experimental test of predator detection rates using groups of free-living emus," Ethology, vol. 109, no. 3, pp. 209-222, 2003.

[20] E. J. Jennifer, M. M. Beck, and S. E. Scheideler, "Behavioral analysis of EMU chicks and breeding adults," Poultry Science, vol. 76, supplement 1, p. 16, 1997.

[21] J. H. Samour, J. Markham, and O. Nieva, "Sexing ratite birds by cloacal examination," Veterinary Record, vol. 115, no. 8, pp. 167$169,1984$.

[22] P. R. Martin and P. P. G. Bateson, Measuring Behavior: An Introductory Guide, CABI, Cambridge University Press, New York, NY, USA, 1993.

[23] P. K. Smith, "The reliability and validity of one-zero sampling: misconceived criticisms and unacknowledged assumptions," The British Educational Research Journal, vol. 11, no. 3, pp. 215220, 1985.

[24] B. Doneley, "Management of captive ratites," in Clinical Avian Medicine, G. Harrison and T. Lightfoot, Eds., vol. 1, chapter 41, pp. 975-990, Spix Publishing, Palm Beach, Fla, USA, 2006.

[25] S. J. J. F. Davies, "Species accounts," in Ratites and Tinamous Part II-Bird Families of the World, C. M. Perrins, W. J. Bock, and J. Kikkawa, Eds., pp. 211-227, Oxford University Press, New York, NY, USA, 2002.

[26] D. Zinner, J. Hindahl, and M. Schwibbe, "Effects of temporal sampling patterns of all-occurrence recording in behavioural studies: many short sampling periods are better than a few long ones," Ethology, vol. 103, no. 3, pp. 236-246, 1997.

[27] D. R. Menon, Welfare of emus during their handling and transport [Ph.D. thesis], University of British Columbia, British Columbia, Canada, 2013, http://creativecommons.org/licenses/ by-nc-nd/2.5/ca/.

[28] J. Altmann, "Observational study of behavior: sampling methods," Behavior, vol. 49, no. 3-4, pp. 227-267, 1974.

[29] A. A. Degen, M. Kam, and A. Rosenstrauch, "Time-activity budget of ostriches (Struthio camelus) offered concentrate feed and maintained in outdoor pens," Applied Animal Behaviour Science, vol. 22, no. 3-4, pp. 347-358, 1989.

[30] D. E. F. McKeegan and D. C. Deeming, "Effects of gender and group size on the time-activity budgets of adult breeding ostriches (Struthio camelus) in a farming environment," Applied Animal Behaviour Science, vol. 51, no. 1-2, pp. 159-177, 1997.
[31] J. B. Williams, W. R. Siegfreid, S. J. Milton et al., "Field metabolism, water requirements, and foraging behavior of wild ostriches in the Namib," Ecology, vol. 74, no. 2, pp. 390-404, 1993.

[32] C. S. de Azevedo, J. B. Ferraz, H. P. Tinoco, R. J. Young, and M. Rodrigues, "Time the role of habitat, time of the day, season and group size," Acta Ethologica, vol. 13, pp. 109-117, 2010.

[33] J. Sales, D. C. Deeming, P. J. U. van Deventer, M. B. Martella, and J. L. Navarro, "Diurnal time-activity budget of adult greater rheas (Rhea americana) in a farming environment," Archiv fur Geflugelkunde, vol. 64, no. 5, pp. 207-210, 2000.

[34] D. B. Stephens and G. C. Perry, "The effects of restraint, handling, simulated and real transport in the pig (with reference to man and other species)," Applied Animal Behaviour Science, vol. 28, no. 1-2, pp. 41-55, 1990.

[35] T. Fuchs, D. Maury, F. R. Moore, and V. P. Bingman, "Daytime micro-naps in a nocturnal migrant: an EEG analysis," Biology Letters, vol. 5, no. 1, pp. 77-80, 2009.

[36] R. Mahan, "Napping is for the birds," Scientific American Mind, vol. 20, article 9, 2009.

[37] D. S. T. Rao, C. Suryanarayana, and K. Padmaja, "Behavior and hematological observations emu," Indian Journal of Veterinary Medicine, vol. 20, pp. 39-40, 2000.

[38] R. M. Herd, "Anatomy and histology of the gut of the Emu," Emu, vol. 1, pp. 43-46, 1985.

[39] P. C. Glatz, "Welfare issues associated with ratite husbandry practices," in The Welfare of Farmed Ratites, P. C. Glatz, C. A. Lunam, and I. A. Malecki, Eds., vol. 2, chapter 6, pp. 111-130, Springer, Heidelberg, Germany, 2011.

[40] R. Dantzer and P. Mormede, "Stress in farm animals: a need for re-evaluation," Journal of Animal Science, vol. 57, pp. 6-19, 1983.

[41] G. J. Mason and N. R. Latham, "Can't stop, won't stop: is stereotypy a reliable animal welfare indicator?" Animal Welfare, vol. 13, pp. 57-69, 2004.

[42] P. C. Glatz, "Effect of declawing on behavior and skin quality of ostriches," in Proceedings of the 3rd International Ratite Science Symposium and 12th World Ostrich Congress, pp. 157162, Madrid, Spain, 2005.

[43] P. C. Glatz, "Ratite toe trimming for ostriches and emus," in Training Manual, Rural Industries Research and Development Corporation Publication no 08/017, pp. 8-83, South Australia, Australia, 2008.

[44] M. A. Mitchell, "Ostrich welfare and transport," in Ostrich Biology, Production and Health, chapter 9, pp. 217-231, CABI, University Press, Cambridge, UK, 1999.

[45] M. Bracke, "Providing cross-species comparisons of animal welfare with a scientific basis," NJAS-Wageningen Journal of Life Sciences, vol. 54, no. 1, pp. 61-75, 2006.

[46] C. M. Sherwin, "The welfare and ethical assessment of housing for egg production," in The Welfare of Domestic Fowl and other Captive Birds, I. J. H. Duncan and P. Hawkins, Eds., chapter 10, pp. 237-258, Springer, Heidelberg, Germany, 2010.

[47] F. McMillan, "Quality of life concerns in animal shelters-part 2: why is it important and how do we measure it?" in Proceeding of the NAVC North American Veterinary Conference on Small Animal and Exotics, pp. 1486-1488, 2009.

[48] J. L. Barnett and P. H. Hemsworth, "The validity of physiological and behavioural measures of animal welfare," Applied Animal Behaviour Science, vol. 25, no. 1-2, pp. 177-187, 1990.

[49] S. Bewg and P. Kent, Emu Catching andHandling, The State of Queensland Department of Primary Industries Fisheries, 
Department of Employment, Economic Development and Innovation, 2008.

[50] C. G. M. Paxton, N. E. Bubier, and D. C. Deeming, "Feeding and pecking behaviour in ostrich (Struthio camelus) chicks in captivity," British Poultry Science, vol. 38, no. 2, pp. 151-155, 1997.

[51] C. Crowther, R. Davies, and W. Glass, "The effect of night transportation on the heart rate and skin temperature of ostriches during real transportation," Meat Science, vol. 64, no. 4, pp. 365-370, 2003.

[52] D. M. Breed and J. Moore, "Homeostasis and time budgets," in Animal Behavior, chapter 4, pp. 99-123, Academic Press, 2011.

[53] L. A. King, "Behavioral evaluation of the psychological welfare and environmental requirements of agricultural research animals: theory, measurement, ethics, and practical implications," ILAR Journal, vol. 44, no. 3, pp. 211-221, 2003.

[54] R. R. Swaisgood, "Current status and future directions of applied behavioral research for animal welfare and conservation," Applied Animal Behaviour Science, vol. 102, no. 3-4, pp. 139-162, 2007.

[55] S. H. Weller and C. L. Bennett, "Twenty-four hour activity budgets and patterns of behavior in captive ocelots (Leopardus pardalis)," Applied Animal Behaviour Science, vol. 71, no. 1, pp. 67-79, 2001.

[56] D. M. Broom and R. D. Kirkden, "Welfare, stress, behavior and pathophysiology," in Veterinary Pathophysiology, R. H. Dunlop and C. H. Malbert, Eds., chapter 11, pp. 337-369, Blackwell, Ames, Iowa, USA, 2004.

[57] G. Manteuffel, B. Puppe, and P. C. Schön, "Vocalization of farm animals as a measure of welfare," Applied Animal Behaviour Science, vol. 88, no. 1-2, pp. 163-182, 2004. 

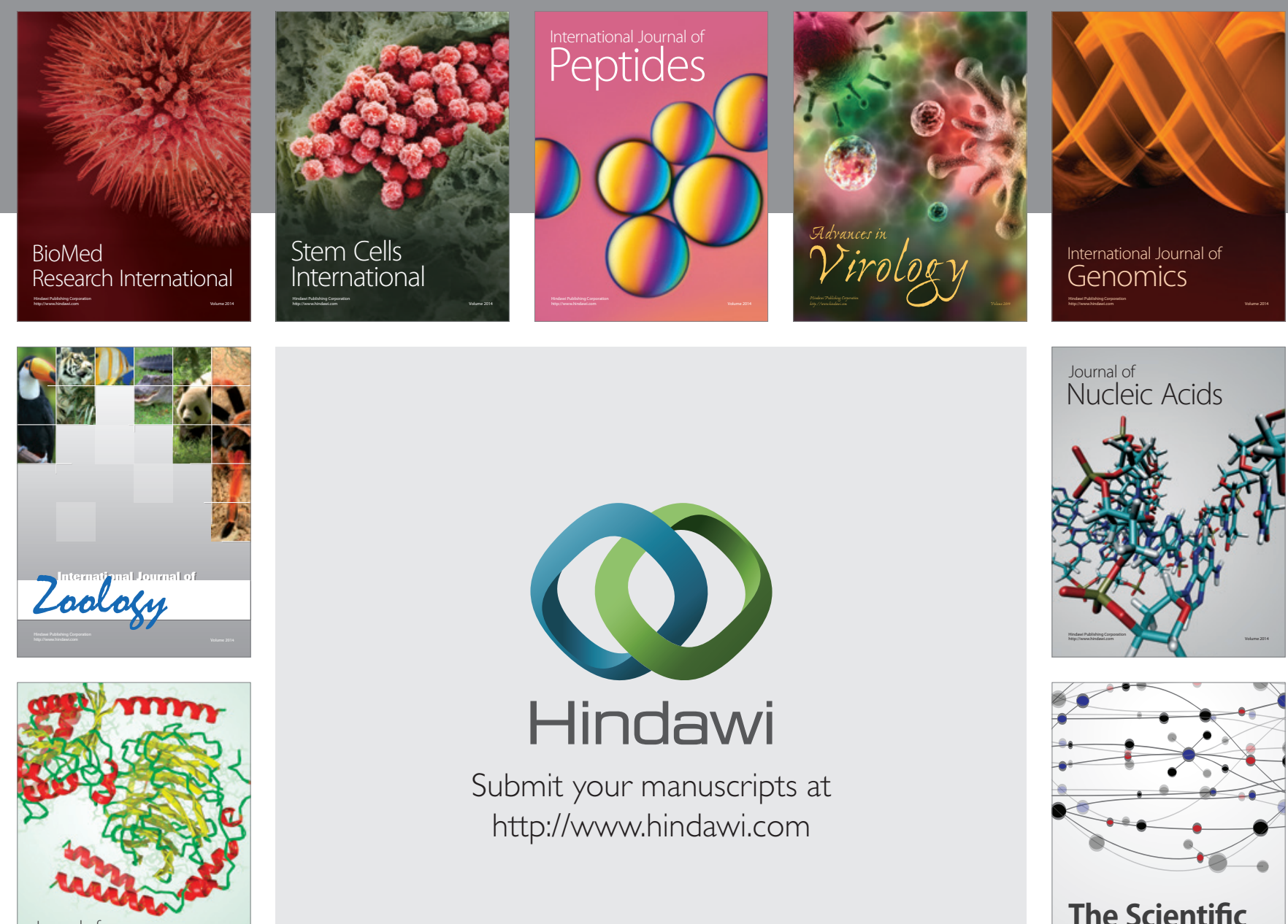

Submit your manuscripts at

http://www.hindawi.com

Journal of
Signal Transduction
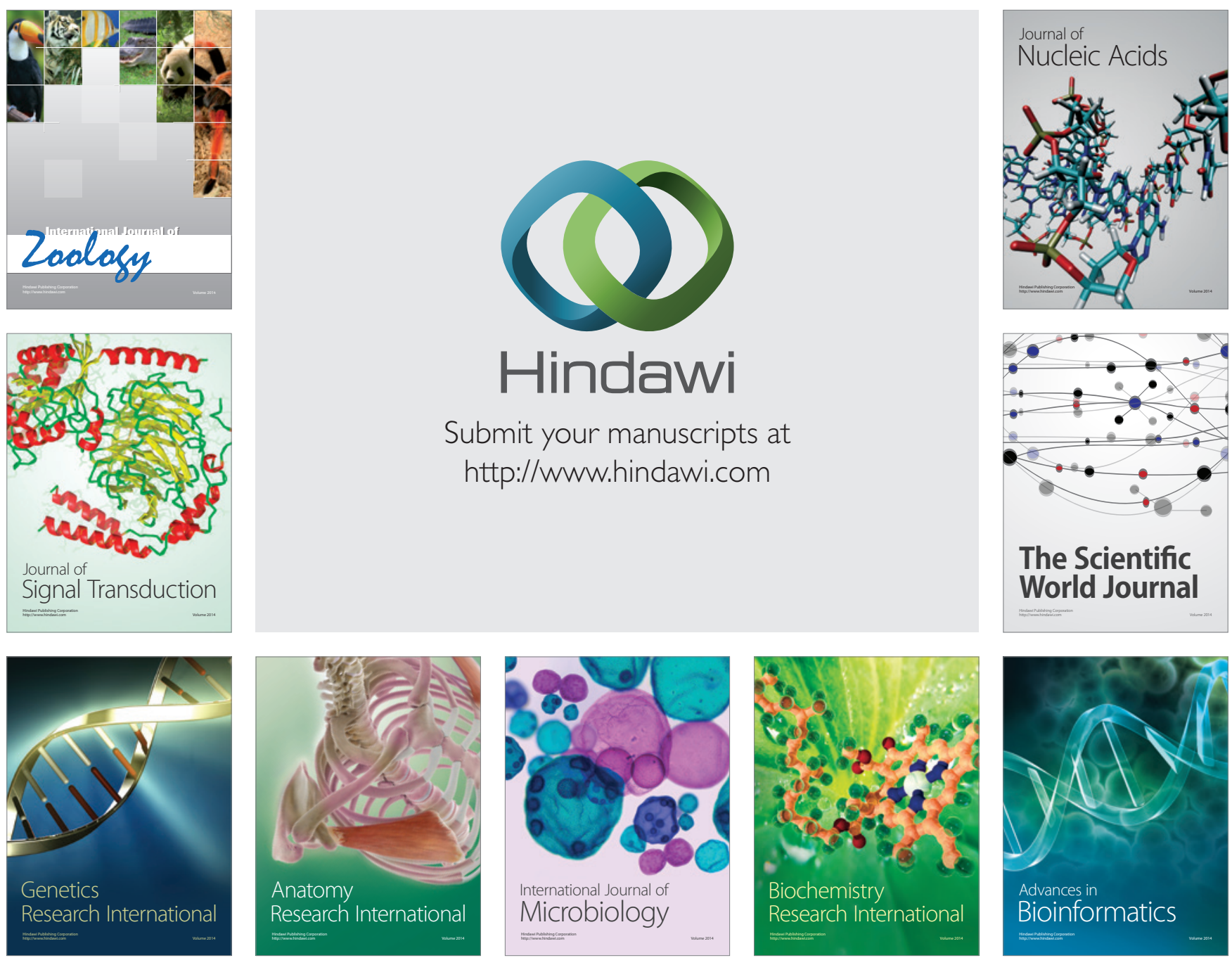

The Scientific World Journal
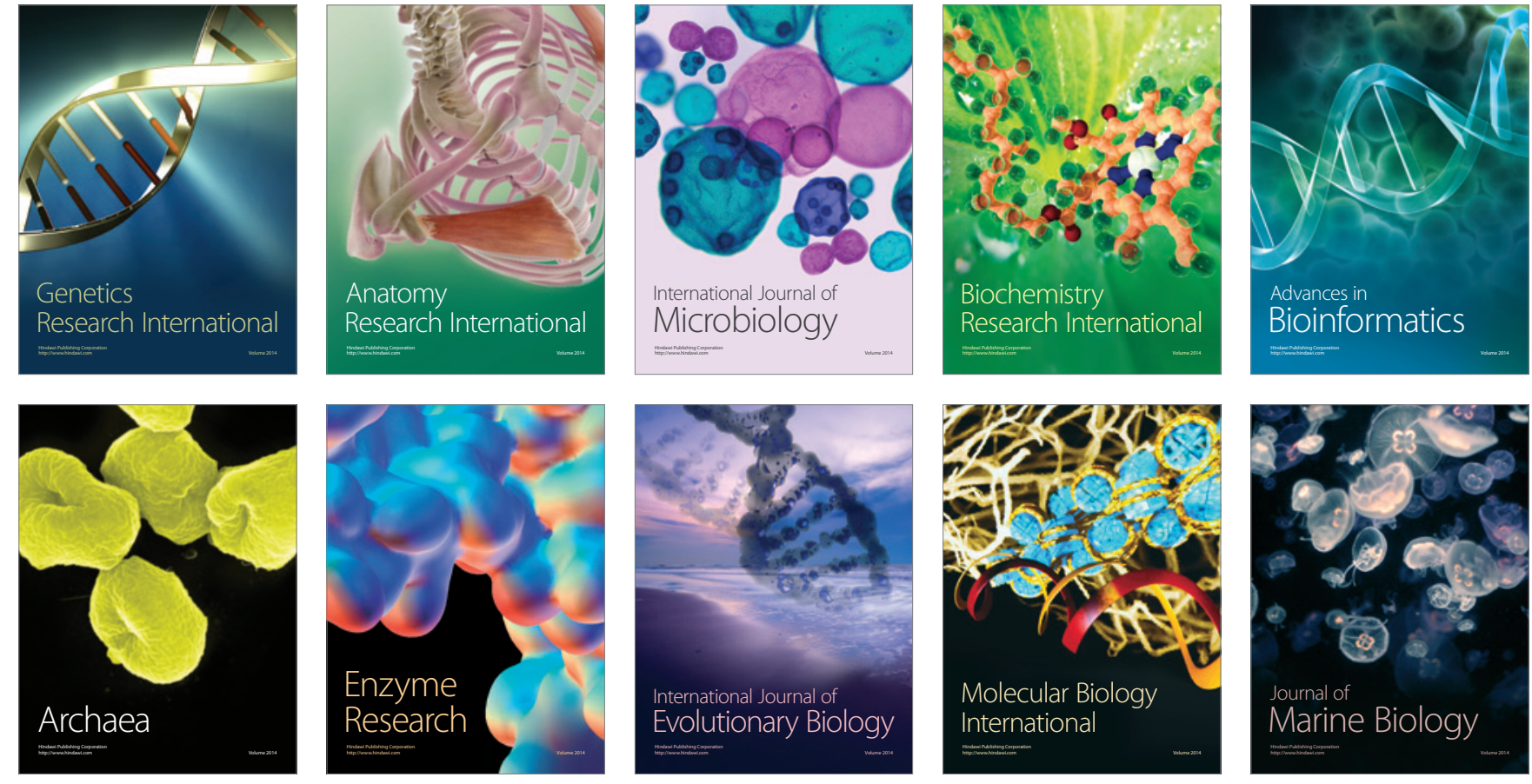